\title{
Squamous Cell Papilloma
}

National Cancer Institute

\section{Source}

National Cancer Institute. Squamous Cell Papilloma. NCI Thesaurus. Code C3712.

A benign epithelial neoplasm characterized by a papillary growth pattern and a

proliferation of neoplastic squamous cells without morphologic evidence of malignancy.

Most frequently it arises in the oral cavity, nasopharynx, larynx, esophagus, vagina, and vulva. 